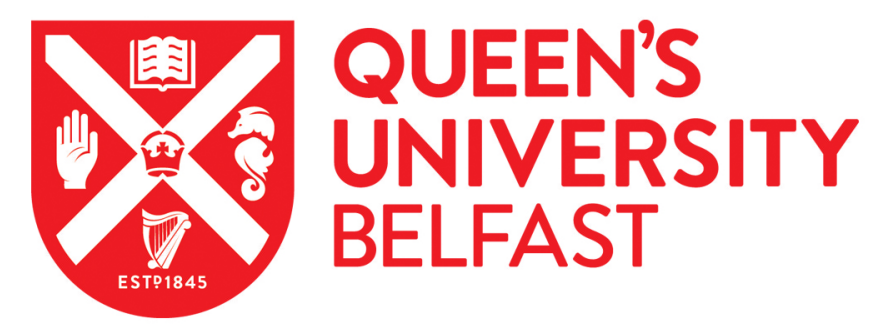

\title{
Continuous flow gas phase photoreforming of methanol at elevated reaction temperatures sensitised by $\mathrm{Pt} / \mathrm{TiO} 2$
}

Caravaca, A., Daly, H., Smith, M., Mills, A., Chansai, S., \& Hardacre, C. (2017). Continuous flow gas phase photoreforming of methanol at elevated reaction temperatures sensitised by Pt/TiO2. Reaction Chemistry \& Engineering, 1, 649-657. https://doi.org/10.1039/C6RE00140H

Published in:

Reaction Chemistry \& Engineering

Document Version:

Peer reviewed version

Queen's University Belfast - Research Portal:

Link to publication record in Queen's University Belfast Research Portal

Publisher rights

Copyright 2016 the authors.

This work is made available online in accordance with the publisher's policies. Please refer to any applicable terms of use of the publisher.

\section{General rights}

Copyright for the publications made accessible via the Queen's University Belfast Research Portal is retained by the author(s) and / or other copyright owners and it is a condition of accessing these publications that users recognise and abide by the legal requirements associated with these rights.

Take down policy

The Research Portal is Queen's institutional repository that provides access to Queen's research output. Every effort has been made to ensure that content in the Research Portal does not infringe any person's rights, or applicable UK laws. If you discover content in the Research Portal that you believe breaches copyright or violates any law, please contact openaccess@qub.ac.uk. 
Continuous flow gas phase photoreforming of methanol at elevated reaction temperatures sensitised by $\mathrm{Pt} / \mathrm{TiO}_{2}$

\author{
A. Caravaca, ${ }^{\mathrm{a}, \mathrm{b} * \mathrm{~T}}$ H. Daly, ${ }^{\mathrm{a}, \mathrm{c}}$ M. Smith, ${ }^{\mathrm{d}}$ A. Mills, ${ }^{\mathrm{a} *} \mathrm{~S}$. Chansai, ${ }^{\mathrm{a}, \mathrm{c}}$ and C. Hardacre ${ }^{\mathrm{a}, \mathrm{c} *}$ \\ ${ }^{a}$ School of Chemistry and Chemical Engineering, Queen's University Belfast, Belfast BT9 5AG \\ ${ }^{b}$ UK Catalysis Hub, Research Complex at Harwell, Rutherford Appleton Laboratory, Harwell Oxford, \\ Oxon OX11 OFA

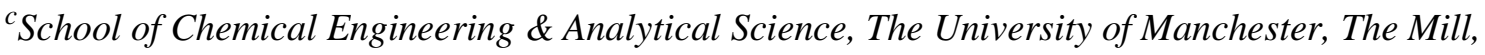 \\ Sackville Street, Manchester, M13 9PL \\ ${ }^{d}$ School of Materials, The University of Manchester, The Mill, Sackville Street, Manchester, M13 9PL \\ *corresponding authors: angel.caravaca@cea.fr; andrew.mills@qub.ac.uk; \\ c.hardacre@manchester.ac.uk \\ ${ }^{\text {† }}$ Present address: CEA, DEN, DRCP/SERA/LCAR, F-30207 Bagnols-sur-Cèze Cedex, France.
}

\begin{abstract}
Gas phase photoreforming of methanol using a $\mathrm{Pt} / \mathrm{TiO}_{2}$ photocatalyst has been performed under flow conditions at elevated temperatures. Comparing the activity of the reforming process as a function of temperature under dark and irradiated conditions shows a significant enhancement in the rate of $\mathrm{H}_{2}$ production using the photo-assisted conditions at temperatures between 100-140 ${ }^{\circ} \mathrm{C}$. At higher temperatures, the effect of irradiation is small with the process dominated by the thermal process. Deactivation of the catalyst was observed under irradiation but the catalyst was easily regenerated using an oxygen treatment at $120{ }^{\circ} \mathrm{C}$. Diffuse Reflectance Infra-red Fourier Transform Spectroscopy (DRIFTS) showed that the activity of the catalyst could be correlated with the presence of the photogenerated trapped electrons. In addition, lower amounts of CO adsorbed on Pt, compared to those observed in the dark reaction, were found for the UV-irradiated systems. It is proposed that CO and adsorbed intermediates, such as formate, can act as inhibitors in the photoreforming process and this is further supported by the observation that, before and after the regeneration process in $\mathrm{O}_{2}$, the $\mathrm{CO}$ and surface adsorbed organic intermediate products are removed and the activity is recovered.
\end{abstract}




\section{Introduction}

Hydrogen is attracting increasing interest as an energy carrier for use in fuel cell devices and although fuel cell technology is already mature, the production of hydrogen still remains a major issue. Currently, nearly all hydrogen is produced using fossil fuels and only $4 \%$ is produced by water electrolysis. ${ }^{1}$ An alternative approach to the production of hydrogen is via the photocatalysed cleavage of water which is an example of the direct conversion of solar into chemical energy. In this area, many studies have been carried out in which a semiconductor photocatalyst is used to sensitise the photocleavage of water into $\mathrm{H}_{2}$ and $\mathrm{O}_{2}{ }^{2}$ However, in general, most visible light-absorbing photocatalysts are unstable and most solar UV absorbing photocatalysts, such as $\mathrm{TiO}_{2}$ are unable to drive the reaction forward without additional electrochemical or chemical (eg. via a $\mathrm{pH}$ gradient) bias. ${ }^{2,3}$ As a consequence, the use of sacrificial electron donors (SEDs), as semiconductor photogenerated hole scavengers, which are able to promote the efficient separation of the photogenerated charge carriers and the accumulation of photogenerated electrons, have been used to facilitate the reduction of water to hydrogen. ${ }^{4}$ This process can be referred to as photocatalytic reforming or, more simply, here as photoreforming, and it leads to a significant enhancement in the production of hydrogen compared to direct water splitting.

As well as fossil fuel-based SEDs, biomass-derived compounds have been demonstrated as effective SEDs in the photoreforming process, since biomass is ultimately derived from $\mathrm{CO}_{2}$ in air, it follows that the production of $\mathrm{CO}_{2}$ during the photoreforming process leads to a near-zero carbon balance. ${ }^{4}$ The photoreforming of biomass-derived compounds, such as methanol, ${ }^{5-8}$ ethanol $^{9,10}$ or glycerol, ${ }^{10-12}$ in aqueous solutions has been studied thoroughly, usually at room temperature. Methanol is an ideal model as a sacrificial reductant and is often used for this purpose and so methanol was used as the SED in this study. The overall photoreforming reaction is as follows:

$\mathrm{TiO}_{2} / \mathrm{Pt}$

$$
\mathrm{CH}_{3} \mathrm{OH}+\mathrm{H}_{2} \mathrm{O} \longrightarrow \mathrm{CO}_{2}+3 \mathrm{H}_{2}
$$

$h v \geq 3.2 \mathrm{eV}$ 
As indicated above, to date, most of the studies regarding the photoreforming of alcohols have been carried out in the liquid phase, using platinised $\mathrm{TiO}_{2}$ and under batch reaction conditions. However, $\mathrm{Kang}^{13}$ reported hydrogen production upon irradiation of a $\mathrm{Fe} / \mathrm{TiO}_{2}$ photocatalyst dispersed in methanol/water solution in a liquid phase batch system in addition to some limited results for a continuous flow system. For the photoreforming of alcohols, working in continuous flow is a very important step in view of the further practical application of the photoreforming process. For the majority of applications, continuous flow operation saves time, energy and costs, increasing the productivity and reducing the transportation costs. In addition, little attention has been given to the effect of temperature.

Interestingly, there have been only a few studies which examined the photoreforming of alcohols (methanol) in the gas phase and most, if not all, have been conducted at room temperature. ${ }^{1,13-16}$ For example, Greaves et al. ${ }^{14}$ carried out the photoreforming of methanol in a batch gas phase system over $\mathrm{Au} / \mathrm{TiO}_{2}$ photocatalysts. Chiarello et al. compared the rates of photoreforming of methanol in the gas phase over $\mathrm{Au} / \mathrm{TiO}_{2},{ }^{1,15} \mathrm{Pt} / \mathrm{TiO}_{2}{ }^{1,16}$ and $\mathrm{Ag} / \mathrm{TiO}_{2}{ }^{1}$ photocatalysts using a closed recirculating gas system.

In this paper we describe the results arising from a study of the UV-driven, photocatalytic steam reforming of methanol over platinised titania in a continuous flow, gas phase system at reaction temperatures much greater than room temperature, i.e. between $100-200{ }^{\circ} \mathrm{C}$. In this work, in-situ DRIFTS has been used to study the effect of UV irradiation on the species adsorbed on the photocatalyst, in order to provide a greater mechanistic insight into the system.

\section{Experimental}

\section{$\underline{2.1 \text { Photo photocatalyst preparation }}$}

$0.2 \mathrm{wt} \% \mathrm{Pt} / \mathrm{TiO}_{2}$ photocatalysts were prepared by wet impregnation of the metal precursor $\left(\mathrm{H}_{2} \mathrm{PtCl}_{6} .6 \mathrm{H}_{2} \mathrm{O}\right)$ onto $\mathrm{TiO}_{2}\left(\mathrm{P} 25\right.$, Degussa) followed by drying at $150{ }^{\circ} \mathrm{C}$ for $2 \mathrm{~h}$ and, thereafter, calcination at $500{ }^{\circ} \mathrm{C}$ for $2 \mathrm{~h}$. The photocatalyst was sieved to ensure that the aggregate size was between 250 and $420 \mu \mathrm{m}$ prior to use. The metal loading was measured using a Perkin Elmer Optima 4300 dv Inductively Coupled Plasma Optical Emission spectrometer (ICP-OES). In its unreduced state the Pt will be mainly in the form of $\mathrm{PtO}_{2}$ and thus the pre-catalyst appears cream coloured. However, upon reduction in the reactor at 200 
${ }^{\circ} \mathrm{C} 5 \% \mathrm{H}_{2} / \mathrm{Ar}$ at $15 \mathrm{~cm}^{3} \mathrm{~min}^{-1}$ for $30 \mathrm{~min}$, the photocatalyst takes on a light grey appearance, as the $\mathrm{PtO}_{2}$ is reduced to $\mathrm{Pt}$.

\subsection{Photocatalyst characterisation}

The total surface area of the as prepared catalyst and catalyst reduced under reaction conditions (used catalyst) were measured using a Micromeritics ASAP2020 and the BET method.

XRD patterns were obtained using a PANalytical X'Pert Pro X-ray Diffractometer using $\mathrm{Cu} \mathrm{K} \mathrm{K}_{\alpha}$ irradiation. Diffractograms were carried out from $10^{\circ}$ to $90^{\circ}$, with a step size of $0.008^{\circ}$. Crystal sizes in the different phases were estimated from line broadening of the corresponding X-ray diffraction peaks using the Scherrer equation. The anatase/rutile ratio was calculated by examining the relative peak intensities of crystalline planes (101) and (111) of anatase and rutile, respectively.

High resolution transmission electron microscope (HRTEM) images, scanning transmission electron microscope (STEM) images and energy dispersive X-ray spectroscopy (EDS) spectrum images were obtained with an FEI Talos F200A microscope equipped with an XFEG electron source and Super-X SDD EDS detectors. The experiment was performed using an acceleration voltage of $200 \mathrm{kV}$ and a beam current of approximately $0.5 \mathrm{nA}$. TEM Images were recorded with an FEI CETA 4k x 4k CMOS camera. STEM images were acquired with a HAADF detector. The sample was supported on a holey carbon film with a 300 mesh copper TEM grid.

\subsection{Photocatalytic activity testing}

The irradiation of the photocatalyst-filled 'S-bend' reactor tube, i.e. the 'photocatalyst bed', at elevated temperatures was undertaken using an in-house developed reactor setup, the main features of which are illustrated in Figure 1(a). The reactor comprised: a semi-cylindrical ceramic fibre heater (Watlow) with quartz cylinder envelope, with the gap between the tube and the heater filled with a ceramic fibre blanket to provide thermal insulation, except for an insulation-free window to allow the irradiation of the heated photocatalyst bed, illustrated in Figure 1(b), which was placed next to the heater semi-cylinder. All illuminations were 
carried out using a $200 \mathrm{~W} \mathrm{Xe} / \mathrm{Hg}$ arc lamp (Oriel), which provided a typically UV irradiance of $19 \mathrm{~mW} \mathrm{~cm}^{-2}$.

To protect the lamp from the heat of the furnace, a second quartz cylinder, concentric to the first but with a diameter $1.5 \mathrm{~cm}$ larger than the inner cylinder, was utilised. Holes were drilled in the table between these cylinders to allow the external cylinder to cool by air convection. A serpentine shaped, i.e. S-bend', Pyrex ${ }^{\mathrm{TM}}$ glass reactor (internal diameter 1.5 $\mathrm{mm}$ ) was used for the photocatalytic experiments (Figure 1b), in which typically, $800 \mathrm{mg}$ of photocatalyst were placed in order to fill the irradiated section of the S-bend reactor. Pyrex ${ }^{\mathrm{TM}}$ cuts off all wavelengths below $300 \mathrm{~nm}$, and so no high energy UVC irradiation from the light source reached the photocatalyst. The serpentine shape increased the catalyst surface area that was exposed to the light compared with a conventional tubular plug flow reactor. The reactor temperature was measured at three points corresponding to the top, middle and bottom of the photocatalyst bed by thermocouples attached to the outer wall of the reactor. The temperature of the furnace was adjusted so that the temperature in the middle of the photocatalyst bed remained constant and at the desired value (Table S1).

The reaction gases supplied by BOC were certified standards of: $\mathrm{Ar}$ (99.999\% purity), $\mathrm{H}_{2}$ (99.999\% purity), 5\% $\mathrm{O}_{2} / \mathrm{Ar}$ and $\mathrm{C}_{2} \mathrm{H}_{4}$ (99.999\% purity); the latter was used as an internal standard and injected into the gas stream at the exit of the reactor. The gas flow was controlled using calibrated mass flowmeters (Brooks) and the water and methanol were fed into the feed stream by separate saturators whose temperature were controlled using recirculating water baths. All lines downstream of the saturators were trace heated to above $100{ }^{\circ} \mathrm{C}$ to prevent condensation. The gas feed into the photoreactor consisted of $3 \%$ methanol plus $10 \%$ water (in Ar) with a total flow of $10 \mathrm{~cm}^{3} \mathrm{~min}^{-1}$ resulting in a weight hourly space velocity of $750 \mathrm{~cm}^{3} \mathrm{~h}^{-1} \mathrm{~g}_{\mathrm{cat}}{ }^{-1}$. The reactor volume was $\sim 0.43 \mathrm{~cm}^{3}$ and, therefore, the gas hour space velocity was $\sim 1398 \mathrm{~h}^{-1}$ with a residence time of $\sim 2.6 \mathrm{~s}$.. The reactants and products were analysed using a Gas Chromatograph (Perkin Elmer) fitted with a Porapak D column with a TCD, for the analysis of $\mathrm{H}_{2}$, and a FID (with methanizer), for the analysis of $\mathrm{CO}, \mathrm{CO}_{2}$, methanol and the ethylene internal standard. At the start of each photoreaction, the reactor was flushed with Ar and cooled to the desired reaction temperature before exposure to the feed and subsequent illumination.

\subsection{In-situ DRIFTS of photoreforming reaction:}


Photoreforming of $0.2 \% \mathrm{Pt} / \mathrm{TiO}_{2}$ photocatalysts was also studied using in-situ DRIFTS utilising an in-house modified environmental chamber (Spectra Tech) which contained a UV LED lamp (365 $\mathrm{nm}$ from LED Engin) positioned $~ 1 \mathrm{~cm}$ above the photocatalyst bed in the top plate of the environmental chamber (Figure 2); the irradiance was typically $35 \mathrm{~mW} \mathrm{~cm}^{-2}$. The photocatalyst was pre-reduced in $5 \% \mathrm{H}_{2} / \mathrm{Ar}$ at $200{ }^{\circ} \mathrm{C}$ for $30 \mathrm{~min}$ at $50 \mathrm{~cm}^{3} \mathrm{~min}^{-1}$ and then the reactor was purged with $\mathrm{Ar}$ and cooled to $100{ }^{\circ} \mathrm{C}$ before exposure to the feed $(3 \% \mathrm{MeOH}$ plus $10 \% \mathrm{H}_{2} \mathrm{O}$ in Ar total flow $50 \mathrm{~cm}^{3} \mathrm{~min}^{-1}$ ). Spectra were recorded (resolution $4 \mathrm{~cm}^{-1}, 32$ scans) under a continuous flow of the methanol/water feed alternating between dark and UV conditions. The reduced photocatalyst was used as the background spectrum and all spectra shown as reported at $\log (1 / R)$ where $R$ is reflectance of photocatalyst under the reaction feed/reflectance of the reduced photocatalyst.

\section{$\underline{3 \text { Results and Discussion: }}$}

\section{$\underline{3.1 \text { Characterisation of } 0.2 \% \mathrm{Pt} / \mathrm{TiO}_{2}}$ :}

The $0.2 \% \mathrm{Pt} / \mathrm{TiO}_{2}$ photocatalyst was characterised by XRD and HRTEM and the results are shown in the supplementary information as well as its total surface area measured by BET. The BET surface area of the fresh catalyst was $53.0 \mathrm{~m}^{2} \mathrm{~g}^{-1}$ and the used catalyst had a BET surface area of $49.1 \mathrm{~m}^{2} \mathrm{~g}^{-1}$. Figure $\mathrm{S} 1$ shows the diffractograms for the pure $\mathrm{TiO}_{2}$ support (P25) and the fresh and used $\mathrm{Pt} / \mathrm{TiO}_{2}$ photocatalyst. In addition, Table S2 summarizes the crystallite size of the $\mathrm{TiO}_{2}$ anatase and rutile phases, together with the anatase phase percentage. No significant modification in crystallinity or crystal phase was found comparing the pure support, or fresh or used catalyst. This is in good agreement with previous studies regarding the range of temperatures for anatase-rutile phase transition, which indicates that temperatures higher than $600{ }^{\circ} \mathrm{C}$ are required. ${ }^{17,18}$ No peaks corresponding to $\mathrm{Pt}$ or $\mathrm{PtO}_{\mathrm{x}}$ were observed which may be a reflection of the low metal loading and/or a high dispersion of Pt. For the catalyst reduced under reaction conditions (used catalyst), a similar XRD pattern was observed with only $\mathrm{TiO}_{2}$ related features found. Pt nanoparticles (2-3 nm) were observed using HRTEM.(Figure S2). This aggregation of Pt may have led to some pore blocking and the small reduction in the BET surface area.

\subsection{Thermal and Photocatalytic activity}


The effect of the UV-vis irradiation on the steam reforming reaction was examined through a series of light-on/light-off cycles as a function of temperature. Figure 3 displays the catalytic activity in the presence and absence of irradiation for the methanol steam reforming reaction over the $0.2 \% \mathrm{Pt} / \mathrm{TiO}_{2}$ catalyst/photocatalyst. The temperature was increased from 100 to $200{ }^{\circ} \mathrm{C}$ in steps of $20^{\circ} \mathrm{C}$ maintaining the temperature for $2 \mathrm{~h}$ at each point $(1 \mathrm{~h}$ under dark then $1 \mathrm{~h}$ under UV irradiation).

\subsubsection{Light off results}

Under dark conditions, an increase in the methanol conversion from $12 \%$ at $100{ }^{\circ} \mathrm{C}$ to $20 \%$ at $180{ }^{\circ} \mathrm{C}$ with a further significant increase to $40 \%$ at $200{ }^{\circ} \mathrm{C}$ was observed. These changes were also reflected in the $\mathrm{H}_{2}$ and $\mathrm{CO}_{2}$ production rates which increased with increasing temperature while the rate of $\mathrm{CO}$ formation remained relatively constant with temperature leading to a gradual decrease in the $\mathrm{CO} / \mathrm{CO}_{2}$ ratio. In addition, trace amounts of methane were formed at a rate of $<10^{-7} \mathrm{~mol} \mathrm{~h}^{-1} \mathrm{~g}_{\mathrm{cat}}{ }^{-1}$. No other C-containing species were observed under thermal conditions.

The thermal (i.e. dark) gas phase catalytic steam reforming of methanol over $\mathrm{Pt} / \mathrm{TiO}_{2}$ has been well-studied. ${ }^{19-21}$ As reported for Group VIII metal catalysts (such as Pt and Pd), the main reactions leading to the production of $\mathrm{H}_{2}$ are methanol steam reforming (the dark equivalent of reaction (1)) and methanol decomposition, i.e.:

$$
\mathrm{CH}_{3} \mathrm{OH} \rightarrow \mathrm{CO}+2 \mathrm{H}_{2}
$$

Figure 4 shows the experimental hydrogen production for both the thermal, and thermal/photoassisted, experiments compared with the predicted hydrogen production according to reactions (1) and (2). The predicted hydrogen production was calculated according to equation (3):

$$
r_{\mathrm{H}_{2} \text { predicted }}=2 \times r_{\mathrm{CO} \exp }+3 \times r_{\mathrm{CO}_{2} \exp }
$$

where $r_{\mathrm{CO} \text { exp }}$ and $r_{\mathrm{CO}_{2} \text { exp }}$ are the hydrogen production rates shown in Figure 3. For the thermal catalytic process, (filled triangles, Figure 3, the straight line with a unity gradient demonstrates that any other reaction intermediates are quickly consumed under the reaction conditions studied, and their concentrations are negligible compared to the production of $\mathrm{CO}$ and $\mathrm{CO}_{2}$. In addition, it shows that reactions (1) and (2) are the dominant thermal catalytic processes on the $\mathrm{Pt} / \mathrm{TiO}_{2}$. The fact that the $\mathrm{CO}$ production does not vary significantly (from 
16 to $20 \times 10^{-5} \mathrm{~mol} \mathrm{~h}^{-1} \mathrm{~g}_{\mathrm{cat}}{ }^{-1}$ ) over the temperature range studied in the dark suggests that methanol decomposition, i.e. reaction (2), is a major background reaction but, at high temperatures, steam reforming, i.e. reaction (1), also become significant; this observation is consistent with previous reported studies. ${ }^{19}$ The formation of $\mathrm{CO}$ relative to $\mathrm{CO}_{2}\left(\mathrm{CO} / \mathrm{CO}_{2}\right.$ ratio shown in Figure 3) provides a measure of the relative rates of reactions (1) and (2). The decrease in ratio with increasing temperature shows that at the higher reaction temperatures steam reforming becomes the dominant route for methanol conversion.

\subsubsection{UV light on results}

Under UV irradiation, enhanced methanol conversion and hydrogen production rates of up to a factor of 2 were observed at all temperatures below $160{ }^{\circ} \mathrm{C}$ relative to reaction carried out without UV light (Figure 3). For example, under irradiation the $\mathrm{H}_{2}$ production was $75 \mathrm{x}$ $10^{-5} \mathrm{~mol} \mathrm{~h}^{-1} \mathrm{~g}_{\mathrm{cat}}{ }^{-1}$ at $100{ }^{\circ} \mathrm{C}$ compared with $40 \times 10^{-5} \mathrm{~mol} \mathrm{~h}^{-1} \mathrm{~g}_{\mathrm{cat}}{ }^{-1}$ under dark conditions. Enhancements were also observed for both $\mathrm{CO}_{2}$ and $\mathrm{CO}$ showing that the photocatalytic process enhances both the decomposition of $\mathrm{MeOH}$, reaction (2), and the photoreforming of ethanol, reaction (1). It is only above $160{ }^{\circ} \mathrm{C}$ that the $\mathrm{CO} / \mathrm{CO}_{2}$ ratio starts to decrease and match the trend of the dark reaction. The latter results indicate that at increasing temperatures above $160{ }^{\circ} \mathrm{C}$ ' the photocatalytic process makes a decreasing contribution to the overall rate of hydrogen generation via reactions (1) and (2), which are increasingly thermally driven. This is also shown by the fact that in the light-driven process the conversion of methanol and the rates of formation for all the products are approximately invariant with temperature below $160{ }^{\circ} \mathrm{C}$. The decrease in $\mathrm{CO} / \mathrm{CO}_{2}$ ratio with increasing temperature above $160{ }^{\circ} \mathrm{C}$ could be due to the steam reforming reaction (1) beginning to dominate with increasing temperature above this point, compared to methanol decomposition reaction (2) or an increase in the water gas shift reaction (4). The latter has been shown to be active at these temperatures over $\mathrm{Pt} / \mathrm{TiO}_{2}{ }^{22}$

$$
\mathrm{CO}+\mathrm{H}_{2} \mathrm{O} \rightarrow \mathrm{CO}_{2}+\mathrm{H}_{2}
$$

As found with the thermally activated process, Figure 4 shows that there is a good agreement with the predicted $\mathrm{H}_{2}$ production from the steam reforming and methanol decomposition reactions under photo-activated conditions demonstrating the lack of byproducts. For example, the small amount of methane production is similar to that found for 
the thermally activated reaction. It should be noted that the extent of direct water splitting using $10 \%$ water only under these conditions is $<5 \times 10^{-5} \mathrm{~mol} \mathrm{~h}^{-1} \mathrm{~g}_{\mathrm{cat}}{ }^{-1}$.

The above results show that, in the dark at low temperatures, the decomposition of $\mathrm{MeOH}$, with concomitant production of $\mathrm{CO}$, is the dominant process. In contrast, under illumination at the same temperatures, i.e. $<160{ }^{\circ} \mathrm{C}$, the photocatalysed steam reforming reaction (1) is a major process. It should be noted that the decomposition of $\mathrm{MeOH}$, reaction (2), is also enhanced by photocatalysis at temperatures $<160^{\circ} \mathrm{C}$.

The rates of hydrogen production are lower than found by Chiarelli et al. ${ }^{1,16}$ using a recirculating gas phase photocatalytic system. Therein, for a wet impregnated $0.5 \% \mathrm{Pt} / \mathrm{TiO}_{2}$ catalyst, the $\mathrm{H}_{2}$ production rate was $775 \times 10^{-5} \mathrm{~mol} \mathrm{~h}^{-1} \mathrm{~g}_{\mathrm{cat}}{ }^{-1}\left(1.55 \mathrm{~mol} \mathrm{~h}^{-1} \mathrm{gpt}^{-1}\right)$ at $55{ }^{\circ} \mathrm{C}$ compared with $75 \times 10^{-5} \mathrm{~mol} \mathrm{~h}^{-1} \mathrm{~g}_{\mathrm{cat}}{ }^{-1}\left(0.375 \mathrm{~mol} \mathrm{~h}^{-1} \mathrm{gPt}^{-1}\right)$ at $100{ }^{\circ} \mathrm{C}$ in the present case. This difference is likely to be associated with the higher flux of photons in both studies and the change in reactor geometry. Importantly, whilst the rate is lower, herein, only trace amounts of methane wereobserved and no other carbon containing species. Chiarelli et al. ${ }^{1,16}$ reported the formation of formic acid, formaldehyde, dimethyl ether and esters as well as methane which may be the result of operating in a recirculating mode.

\subsubsection{In-situ DRIFTS of the photoreforming of methanol:}

To study the effect of irradiation upon surface adsorbed species, in-situ DRIFTS was performed under a methanol/water feed at temperatures between 100 and $180{ }^{\circ} \mathrm{C}$ switching between dark and light conditions. Figure 5 shows the DRIFT spectra for the reaction with and without irradiation at $100{ }^{\circ} \mathrm{C}$. In the dark at $100{ }^{\circ} \mathrm{C}$, the species adsorbed on the $\mathrm{Pt} / \mathrm{TiO}_{2}$ photocatalyst include undissociated methanol with bands at 2947, $2844 \mathrm{~cm}^{-1}$ and $1070 \mathrm{~cm}^{-1}$ ( $v_{\mathrm{as}}\left(\mathrm{CH}_{3}\right), v_{\mathrm{s}}\left(\mathrm{CH}_{3}\right)$ and $\left.v_{\mathrm{s}}(\mathrm{C}-\mathrm{O})\right)$, respectively, and methoxy groups with bands at 2924 and $2823 \mathrm{~cm}^{-1}\left(v_{\mathrm{as}}\left(\mathrm{CH}_{3}\right)\right.$ and $\left.v_{\mathrm{s}}\left(\mathrm{CH}_{3}\right)\right), 1463$ and $1437 \mathrm{~cm}^{-1}\left(\delta_{\mathrm{a}}\left(\mathrm{CH}_{3}\right)\right.$ and $\delta_{\mathrm{s}}\left(\mathrm{CH}_{3}\right)$ and $1140 \mathrm{~cm}^{-1}$ due to $v(\mathrm{C}-\mathrm{O})$ of methoxy groups. ${ }^{23,24}$ The formation of methoxy groups has been observed on $\mathrm{TiO}_{2}$ supported photocatalysts through exchange with hydroxyl groups on the support. This results in a broad negative band between 3500 and $3700 \mathrm{~cm}^{-1}$ as methanol adsorbs/dissociates on the titania surface. Formates are also observed with bands at 1559, 1360 due to $v_{\text {as }}(\mathrm{COO})$ and $v_{\mathrm{s}}(\mathrm{COO})$ and $1379 \mathrm{~cm}^{-1}$ due to C-H of bidentate formate species. ${ }^{25}$ Adsorption of CO on Pt was also observed with bands at 2072 and $2030 \mathrm{~cm}^{-1}$ due to linear adsorption on Pt metal. This is expected given that methanol decomposition to $\mathrm{CO}$ and $\mathrm{H}_{2}$ 
via reaction (2) occurs in the dark even at low temperatures. Interestingly, the adsorption of CO on Pt under dark conditions is in contrast to the DRIFTS-MS study of Highfield et al., wherein over a $1 \% \mathrm{Pt} / \mathrm{TiO}_{2}$ catalyst, $\mathrm{CO}$ adsorption on $\mathrm{Pt}$ was only observed following exposure of $1 \% \mathrm{Pt} / \mathrm{TiO}_{2}$ to methanol/water in the presence of irradiation albeit this was under batch conditions and at much lower $\left(<70{ }^{\circ} \mathrm{C}\right)$ temperatures than used here. ${ }^{26}$

Under irradiation, the only major change in the DRIFT spectra is a broad absorbance increase across the entire spectrum from 1000-2500 $\mathrm{cm}^{-1}$ (Figure 5). The increasing absorbance for $\mathrm{TiO}_{2}$ and $\mathrm{TiO}_{2}$-based photocatalysts has been attributed to IR absorbance of the UV generated electrons in shallow trapped states of the conduction band electrons in $\mathrm{TiO}_{2}$ with the maximum observed at $\sim 1800 \mathrm{~cm}^{-1} \cdot 23,27$ The small changes above $3000 \mathrm{~cm}^{-1}$ are likely to be changes in the surface hydroxyl species on exposure to irradiation. In this study, the change in absorbance was only observed for $0.2 \% \mathrm{Pt} / \mathrm{TiO}_{2}$ (or $\mathrm{TiO}_{2}$ ) when exposed to methanol only or methanol plus water feeds and at temperatures up to $180{ }^{\circ} \mathrm{C}$, i.e. no change in absorbance was observed at $200{ }^{\circ} \mathrm{C}$ under the same reaction conditions. This observation suggests that in the gas phase the reduction of water to hydrogen at the Pt sites is the ratedetermining step, i.e. hole trapping is rapid and, as a result, photogenerated electrons accumulate, because the reduction of $\mathrm{H}_{2} \mathrm{O}$ to $\mathrm{H}_{2}$ on the Pt particles is rate-determining. This observation is supported by the in situ FT IR and time resolved study on reaction (1) reported by Chen et al., ${ }^{23}$ who report that 'the decay rate of the [photo-generated] long-lived electrons correlates well with the activity of $\mathrm{H}_{2}$ production' and that 'the yield of long-lived electrons could be responsible for the activity of $\mathrm{H}_{2}$ production'.

The extent of change in absorbance under UV irradiation ( $\triangle \mathrm{Abs}$ at $1800 \mathrm{~cm}^{-1}$ ) provides an indication of the population of the photogenerated, shallow-trapped electrons. As stated above, the trapped electron population for $0.2 \% \mathrm{Pt} / \mathrm{TiO}_{2}$ decreases with increasing reaction temperature (Figure 6), which suggests that electron-hole recombination becomes increasingly rapid with increasing temperature and this can be related to the observation that, at elevated temperatures, little or no enhancement in the methanol conversion and formation rate of $\mathrm{H}_{2}$ was found under irradiation compared with the dark reaction (Figure 3).

At $100{ }^{\circ} \mathrm{C}$, exposure of the photocatalyst to UV light caused a rapid depletion of $\sim 20 \%$ in the Pt-CO band area for the duration of exposure to UV light (Figure 7). When the UV light was switched off, the Pt-CO band area recovered to a value similar to that found before the $\mathrm{Pt} / \mathrm{TiO}_{2}$ photocatalyst was irradiated. This UV-induced decrease in Pt-CO band area was 
observed at temperatures up to $180{ }^{\circ} \mathrm{C}$ with the extent of the change in band area decreasing as the reaction temperature increased (Figure 7). Interestingly, from the results illustrated in Figure 3 for the same system the rate of formation of CO was also enhanced under UV conditions. Thus, the decrease in adsorbed $\mathrm{CO}$ on Pt observed using in situ DRIFTS is associated with the photocatalyst becoming more active with regard to the steam-reforming reaction (1). This suggests that CO adsorption impedes reaction (1) so that an initial key step is the photocatalysed removal of $\mathrm{CO}$ from the Pt, so as to allow reaction (1) to proceed more efficiently.

\subsection{3: Photocatalytic Mechanism}

Mechanistic interpretation of the above results is complicated by the fact that at temperatures both reactions (1) and (2) are promoted thermally and photocatalytically. However, at $100{ }^{\circ} \mathrm{C}$ the reforming reaction (1) appears largely due to photocatalysis, resulting in a significant increase in the rate of $\mathrm{CO}_{2}$ production upon UV illumination. A brief outline of the proposed photocatalytic mechanism is given below.

The mechanism for the reforming of methanol photocatalysed by $\mathrm{Pt} / \mathrm{TiO}_{2}$ is still the subject of much debate with many alternative mechanisms, in which most, or part of the hydrogen generated is derived from thermal, rather than photochemical, versions of reactions (1) and (2). ${ }^{10,15,23,25}$ Herein, we adopt a popular interpretation, based on an electron flux matching approach, ${ }^{23,28}$ often used in photocatalysis, which has its origins in photoelectrochemistry and the interpretation that a platinised $\mathrm{TiO}_{2}$ particle can be viewed as a micro-photoelectrochemical cell in which the $\mathrm{TiO}_{2}$ functions as a photoanode and the Pt as a 'dark' cathode. Consistent with the flux-matching mechanism, it is worth noting that the photo-oxidation of methanol (at a $\mathrm{TiO}_{2}$ photoanode), and concomitant dark reduction of water to hydrogen, is a very well-studied process. ${ }^{29}$

In the flux-matching mechanism, after the photogeneration of an electron-hole pair (5) on the $\mathrm{TiO}_{2}$ photocatalyst particles , i.e.

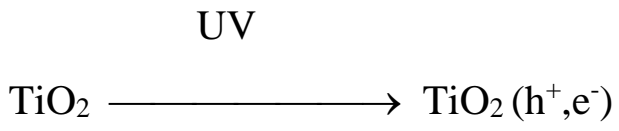


the rate of consumption of photogenerated electrons is matched by that of the holes, $R$. In the absence of a sacrificial electron donor such as $\mathrm{MeOH}$, the value of $R$ is effectively the rate of recombination of the photogenerated electrons and holes to generate heat, $\Delta$, i.e.

$$
\mathrm{TiO}_{2}\left(\mathrm{~h}^{+}, \mathrm{e}^{-}\right) \longrightarrow \mathrm{TiO}_{2}+\Delta
$$

In the presence of a SED, the overall rate of reaction of the holes, $R_{h}$, with $\mathrm{MeOH}$ and subsequent reaction intermediates, will then be matched by the overall rate of reaction of the electrons, $R_{e}$. If $\mathrm{Pt}$ and $\mathrm{H}_{2} \mathrm{O}$ are present, as in this work, the usual fate of the photogenerated electrons will be trapping by the dispersed Pt particles on the $\mathrm{TiO}_{2}$ and the subsequent reduction of water to $\mathrm{H}_{2},{ }^{23,30,31}$ i.e.

$$
2 \mathrm{e}^{-}+2 \mathrm{H}_{2} \mathrm{O} \longrightarrow \mathrm{H}_{2}+2 \mathrm{OH}^{-}
$$

In contrast, the photo-oxidation of $\mathrm{MeOH}$ by the photogenerated holes is believed ${ }^{16,30,31}$ to occur on the surface of $\mathrm{TiO}_{2}$, forming intermediate levels of formaldehyde and formic acid before ultimately yielding $\mathrm{CO}_{2},{ }^{26,28}$ i.e.

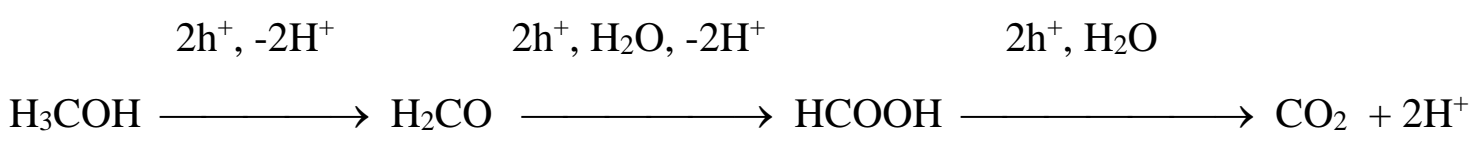

Support for this overall mechanism, which will give the observed 3:1 yield of $\mathrm{H}_{2}$ to $\mathrm{CO}_{2}$, is provided by previous observations ${ }^{23,26,28}$ as well as the present study. Possibly the strongest piece of evidence for the above, all photocatalytic, no thermal, mechanism, derives from the recent work of Kandiel et al., who have shown, through isotopic labelling studies that the $\mathrm{H}_{2}$ produced by this system is mainly produced by the reduction of protons originating from water. ${ }^{28}$ In this work, in agreement with previous studies, ${ }^{26}$ the DRIFTS reveals the photo-generation of formaldehyde and formic acid/formate. Interestingly, here we find clear evidence for the photogeneration of formate, i.e. its ambient surface level increases under irradiation and stops under dark conditions. In contrast, Highfield et al. 
attributed the formate changes are due to a thermal process that leads to some thermal $\mathrm{H}_{2}$ mechanism being present. ${ }^{26}$

Although $\mathrm{MeOH}$ dehydrogenates on $\mathrm{Pt}$ in the dark, via reaction (2) and the $\mathrm{CO}$ adsorbs on the Pt, from the observed drop in Pt-CO signal in DRIFTS with illumination, this process appears to be reduced significantly, upon illumination of the $\mathrm{Pt} / \mathrm{TiO}_{2}$ photocatalyst. This may be associated with the negative effect on the adsorption process, of charging of the $\mathrm{Pt}$ particles by the photogenerated electrons and their subsequent reaction via reaction (3). ${ }^{26}$ The observed increase in background IR absorbance observed in DRIFTS, is compatible with the above flux-matching mechanism, ${ }^{26-28}$ assuming that reaction (7) is sufficiently slow as to allow the photogenerated electrons to accumulate on the $\mathrm{TiO}_{2}$, as $\mathrm{Ti}(\mathrm{III})$, which are often referred to as free conduction band electrons, although they are in fact trapped electrons, and referred to here as such. ${ }^{32}$

In contrast to the photocatalytic system, in the dark, at low temperatures the $\mathrm{Pt} / \mathrm{TiO} 2$ catalyst appears to mediate predominately reaction (2), the dehydrogenation of $\mathrm{MeOH}$ (i.e. methanol decomposition), rather than the steam reforming process, reaction (1), see Figure 2. As the temperature is elevated, the latter reaction plays an increasingly important role, presumably as the water-gas shift reaction starts to dominate, as is often seen with $\mathrm{PGM} / \mathrm{TiO}_{2}$ thermal catalysts. ${ }^{33-35}$ DRIFTS shows the presence of methoxy and formate species, both of which have been seen before for $\mathrm{Au} / \mathrm{TiO}_{2}$ catalysts $^{34,35}$ and have been accounted for in a proposed mechanism involving anion vacancies on the $\mathrm{TiO}_{2}{ }^{35}$

\section{$\underline{\text { 3.2.4 Deactivation and regeneration of } 0.2 \% \mathrm{Pt} / \mathrm{TiO}_{2}:}$}

While a UV enhancement in the steam reforming reaction (1) was observed, using the $0.2 \% \mathrm{Pt} / \mathrm{TiO}_{2}$ at $120^{\circ} \mathrm{C}$ over $1 \mathrm{~h}$ (Figure 3 ), for longer irradiations a slow deactivation of the photocatalyst was observed (Figure 8). To regenerate the original activity of the photocatalyst, the latter was UV irradiated in-situ in an $\mathrm{O}_{2} / \mathrm{H}_{2} \mathrm{O}$ stream for $2 \mathrm{~h}$ at the same temperature $\left(120^{\circ} \mathrm{C}\right)$, in order to promote the photocatalysed oxidation of any adsorbed Ccontaining compounds, such as $\mathrm{CO}$ and formate, that are probably responsible for impeding the overall photocatalytic process. There may also be some carbon deposition on the surface although the mass balance of the reaction is close to quantitative indicating that any carbon deposition is likely to be small. Figure 8 shows that this treatment resulted in catalyst 
regeneration. Importantly, this effect is only associated with the oxygen, treatment under $\mathrm{H}_{2} \mathrm{O} / \mathrm{Ar}$, with or without UV, did not result in reactivation of the catalyst (Figure 9). In-situ DRIFTS performed under the $\mathrm{O}_{2}$ regeneration treatment after $16 \mathrm{~h}$ of photoreforming reaction at $120^{\circ} \mathrm{C}$ showed complete removal of all $\mathrm{CO}$ adsorbed on Pt with formation of gas phase $\mathrm{CO}_{2}$. This is in line with other studies which have reported that the oxidation of $\mathrm{CO}$ on $\mathrm{Pt} / \mathrm{TiO}_{2}$ photocatalysts is very efficient under high $\mathrm{O}_{2} / \mathrm{CO}$ ratios at temperatures higher than $100{ }^{\circ} \mathrm{C} .{ }^{36}$ Interestingly, for both the as prepared catalyst and the regenerated catalyst a small induction period is observed. This may be associated with photo-reduction of the catalyst surface. Whilst this is clear following the oxidative regenerative treatment, prior to the initial reaction, the catalyst is pre-reduced. However, in the latter case it should be noted that, prior to irradiation, the system was equilibrated with the gas feed where the water can surface oxidise the catalyst which then leads to the induction period.

\section{Conclusions}

In this study, a novel photocatalytic reactor was designed and utilised to probe the continuous flow photoreforming of methanol at elevated temperatures over a $\mathrm{Pt} / \mathrm{TiO}_{2}$ photocatalyst. A significant UV enhanced activity was observed at temperatures between 100 and $140{ }^{\circ} \mathrm{C}$ above which the photocatalyst began to exhibit a significant background thermal activity so that the difference in activity between dark and UV irradiated reactions is reduced markedly. The temperature range where enhanced steam reforming photocatalytic activity was observed correlated with the establishment of a clearly discernible population of photogenerated, trapped electrons as well as with the reduction in the amount of CO adsorbed on Pt as monitored by in-situ DRIFTS. The presence of increasing amounts of strongly adsorbed CO/intermediates on the photocatalyst during the reaction is proposed to be the cause of the gradual deactivation under photoreforming conditions, although this can be reversed, and the photocatalyst regenerated, by irradiating the photocatalyst in humid oxygen.

\section{Acknowledgements}

UK Catalysis Hub is kindly thanked for resources and support provided via our membership of the UK Catalysis Hub Consortium and funded by EPSRC (Grant no: EP/K014706/1). 
Open access data can be obtained from the University of Manchester research portal.

\section{References}

$1 \quad$ G.L. Chiarello, M.H. Aguirre and E. Selli, J. Catal., 2010, 273, 182-190.

$2 \quad$ A. Fujishima and K. Honda, Nature, 1972, 238 37-38.

3 P. Deák, J. Kullgren, B. Aradi, T. Frauenheim and L. Kavan, Electrochimica Acta, 2016, 199, 27-34.

4 O. Carp, C.L. Huisman and A. Reller, Prog. Solid State Chem., 2004, 32, 33-177.

5 L.S. Al-Mazroai, M. Bowker, P. Davies, A. Dickinson, J. Greaves, D. James and L. Millard, Catal. Today, 2007, 122, 46-50.

6 H. Bahruji, M. Bowker, P.R. Davies, J. Kennedy and D.J. Morgan, Int. J. Hydrogen Energ., 2015, 40, 1465-1471.

7 T. Chen, Z. Feng, G. Wu, J. Shi, G. Ma, P. Ying and C. Li, J. Phys. Chem. C, 2007, 111, 8005-8014.

8 T. Ishii, H. Kato and A. Kudo, J. Photoch. Photobio A, 2004, 163, 181-186.

9 M. Bowker, C. Morton, J. Kennedy, H. Bahruji, J. Greves, W. Jones, P.R. Davies, C. Brookes, P.P. Wells and N. Dimitratos, J. Catal., 2014, 310, 10-15.

10 M. Bowker, Green Chem., 2011, 13, 2235-2246.

11 M. Bowker, P.R. Davies and L.S. Al-Mazroai, Catal. Lett., 2009, 128, 253-255.

12 V.M. Daskalaki and D.I. Kondarides, Catal. Today, 2009, 144, 75-80.

13 M. Kang, J. Mol. Catal. A, 2003, 197, 173-183.

14 J. Greaves, L. Al-Mazroai, A. Nuhu, P. Davies and M. Bowker, Gold Bull., 2006, 39, 216-219.

15 G.L. Chiarello, L. Forni and E. Selli, Catal. Today, 2009, 144, 69-74.

16 G.L. Chiarello, D. Ferri and E. Selli, J. Catal., 2011, 280, 168-177.

17 E.P. Melián, M.N. Suárez, T. Jardiel, J.M.D. Rodríguez, A.C. Caballero, J. Araña, D.G. Calatayud and O.G. Díaz, Appl. Catalysis B, 2014, 152-153, 192-201.

18 Q. Xu, Y. Ma, J. Zhang, X. Wang, Z. Feng and C. Li, J. Catal., 2011, 278, 329-335.

19 N. Takezawa and N. Iwasa, Catal. Today, 1997, 36, 45-56.

20 W.C. Lin, W.D. Yang, I.L. Huang, T.S. Wu and Z.J. Chung, Energy Fuels, 2009, 23, 2192-2196.

21 N. Iwasa and N. Takezawa, Top. Catal., 2003, 22, 215-224.

22 P. Panagiotopoulou and D. I. Kondarides, J. Catal., 2004, 225, 327-336.

23 T. Chen, Z. Feng, G. Wu , J. Shi, G. Ma, P. Ying and C. Li, J. Phys. Chem. C, 2007, 111, 8005-8014.

24 W.-C. Wu, C.-C. Chuang and J.-L. Lin, J. Phys. Chem. B, 2000, 104, 8719-8724;; D. A. Panayotov, S. P. Burrows and J. R. Morris, J. Phys. Chem. C, 2012, 116, 6623-6635.

25 L.-F. Liao, W.-C. Wu , C.-Y. Chen and J.-L. Lin, J. Phys. Chem. B, 2001, 105, 76787685, P. A. Dilara and J. M. Vohs, J. Phys. Chem., 1993, 97, 12919-12923.

26 J.G. Highfield, M.H. Chen, P.T. Nguyen and Z. Chen, Energy, Environ. Sci., 2009, 2, 991-1002.

27 A. Yamakata, T.-a. Ishibashi and H. Onishi, J. Phys. Chem. B, 2002, 106, 9122-9125; A. Yamakata, T.-a. Ishibashi and H. Onishi, J. Phys. Chem. B, 2003, 107, 9820-9823.

28 J.M. Kesselman, G.A. Shreve, M.R. Hoffmann and N. S. Lewis, J. Phys. Chem., 1994, 98, 13385-13395. 
29 G. Nogami and J.H. Kennedy, J. Electrochem Soc. 1989, 136, 2583-2588.

30 T.A. Kandiel, I. Ivanova and D.W. Bahnemann, Energy, Environ. Sci., 2014, 7, $1420-$ 1425.

31 G.N. Nomikos, P. Panagiotopoulou, D.I. Kondarides and X.E. Verykios, Appl. Catal. B, 2014, 146, 249-257.

32 G. Pacchioni, ChemPhysChem, 2003, 4, 1041-1047.

33 V. G. Deshmane, S.L. Owen, R.Y. Abrokwah and D. Kuila, J. Mol.. Catal. A, 2015, 408, 202-213.

34 K. Kahler, M.C. Holz, M. Rohe, A.C. van Veen and M. Muhlet, J. Catal., 2013, 299, 162-170.

35 A. Nuhu, J. Soares, M Gonzalz-Herra, G. Hussain and M. Bowker, Top. Catal., 2007, 44, 293-297.

36 H. Einaga, N. Urahama, A. Tou and Y. Teraoka, Catal. Lett., 2014, 144, 1653-1660. 
(a)

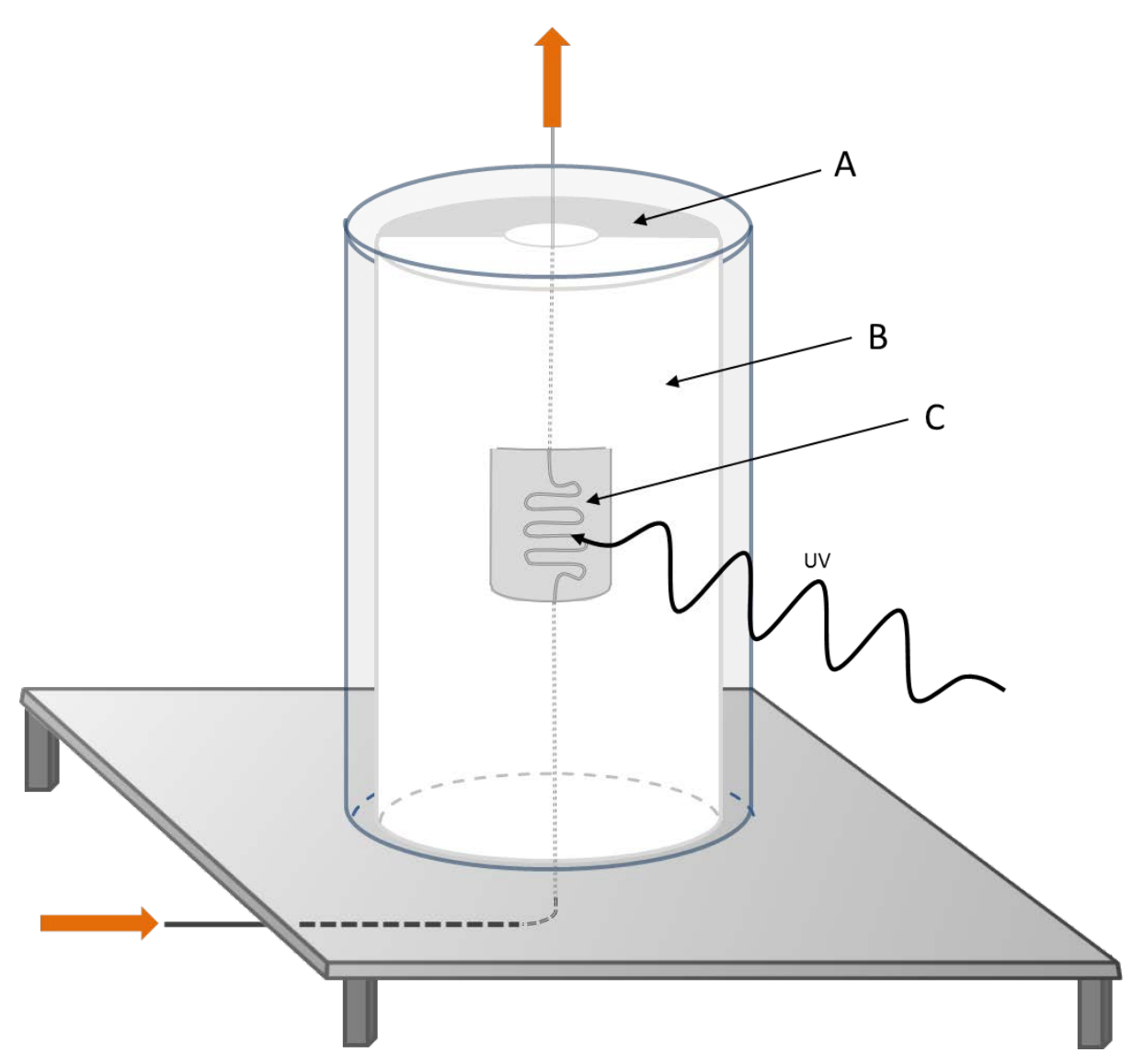

(b)
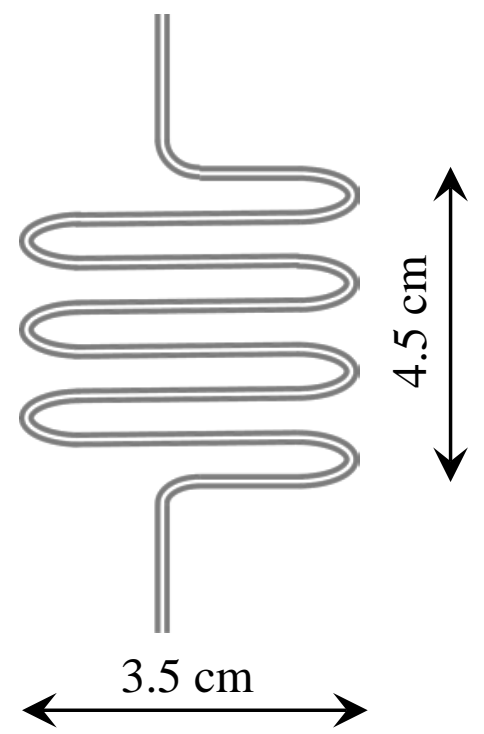

Figure 1. (a) Schematic representation of the overall reactor set up, showing: (A) the semicylidrical heater, (B) the thermal insulation and (C) the 'S-bend' reactor tube, all contained in an inner quartz tube, with an outer one for further insulation (the arrows indicate the direction of the reaction gas flow, and (b) expanded view of the photocatalyst filled 'S-bend' quartz reactor tube (i.d. $1.5 \mathrm{~mm}$ ). 


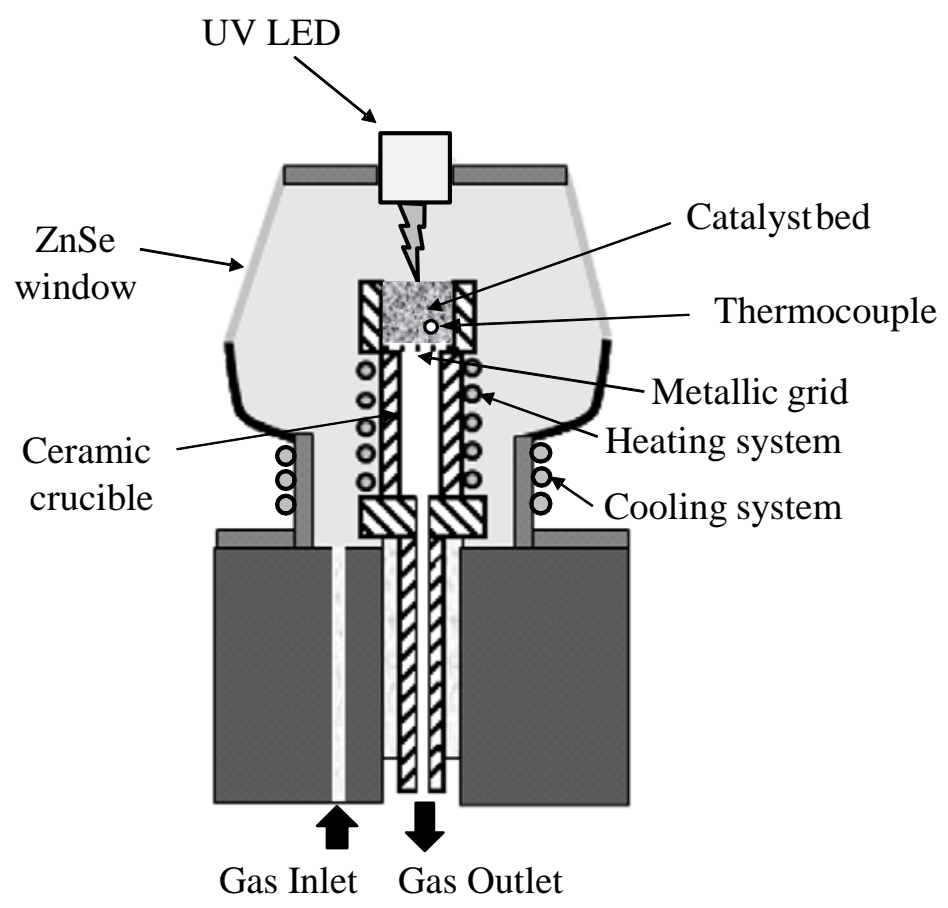

Figure 2: Schematic of photocatalytic in-situ DRIFTS setup. 

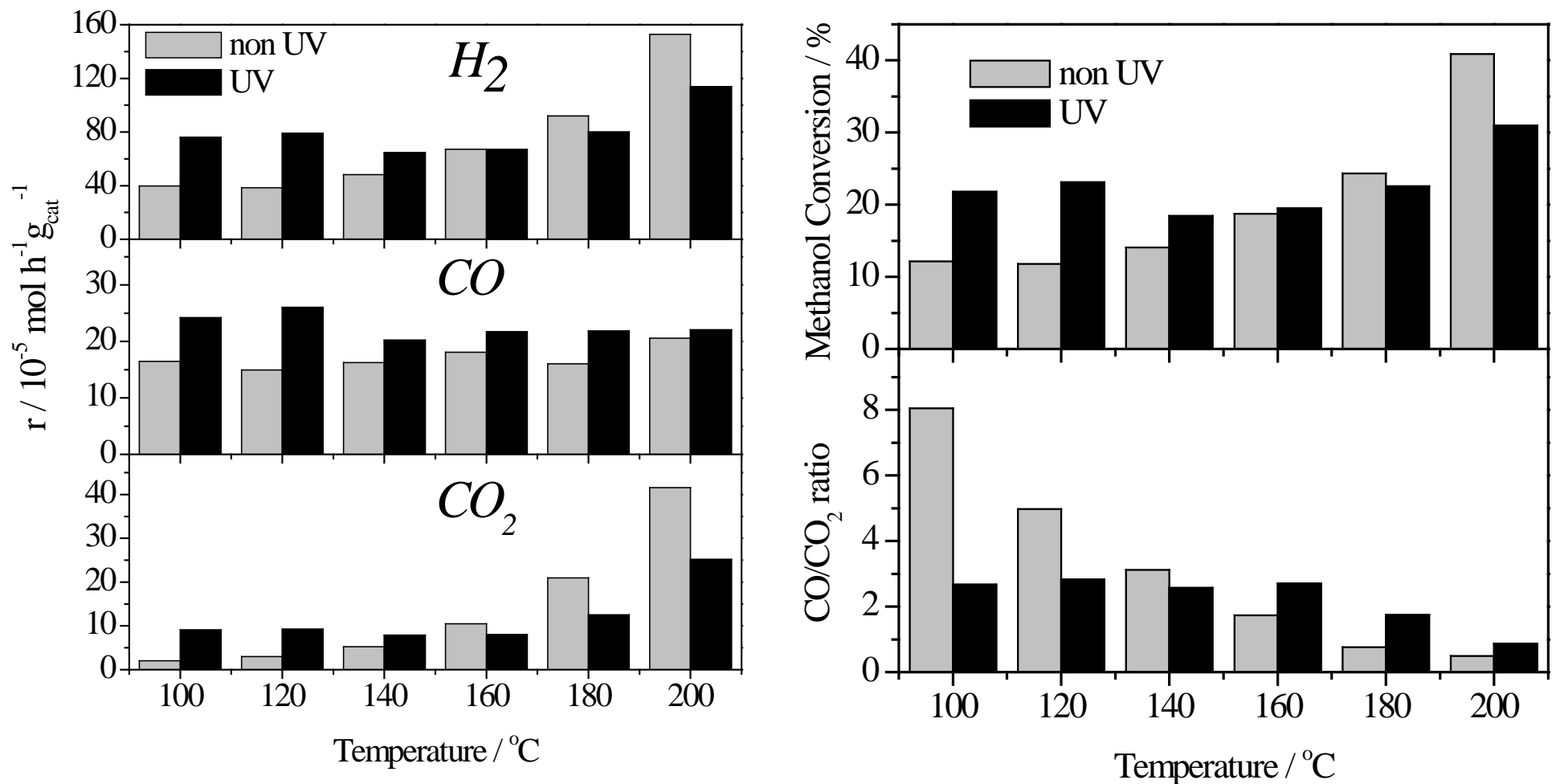

Figure 3. Effect of the reaction temperature and the photoirradiation of the catalyst in the activity for methanol steam reforming. Reaction conditions: $800 \mathrm{mg}$ catalyst $\mathbf{0 . 2 \%} \mathbf{P t} / \mathbf{T i O}_{2}$ (P25), $120{ }^{\circ} \mathrm{C}, 5 \% \mathrm{MeOH} / 10 \% \mathrm{H}_{2} \mathrm{O}$, Total flow $10 \mathrm{~cm}^{3} \mathrm{~min}^{-1}$ (Ar carrier). Photoirradiation with $200 \mathrm{~W} \mathrm{Xe/Hg} \mathrm{lamp.} \mathrm{The} \mathrm{methanol} \mathrm{conversion} \mathrm{value} \mathrm{corresponds} \mathrm{to} \mathrm{that} \mathrm{measured} \mathrm{after}$ $1 \mathrm{~h}$ (in the dark or UV light). 


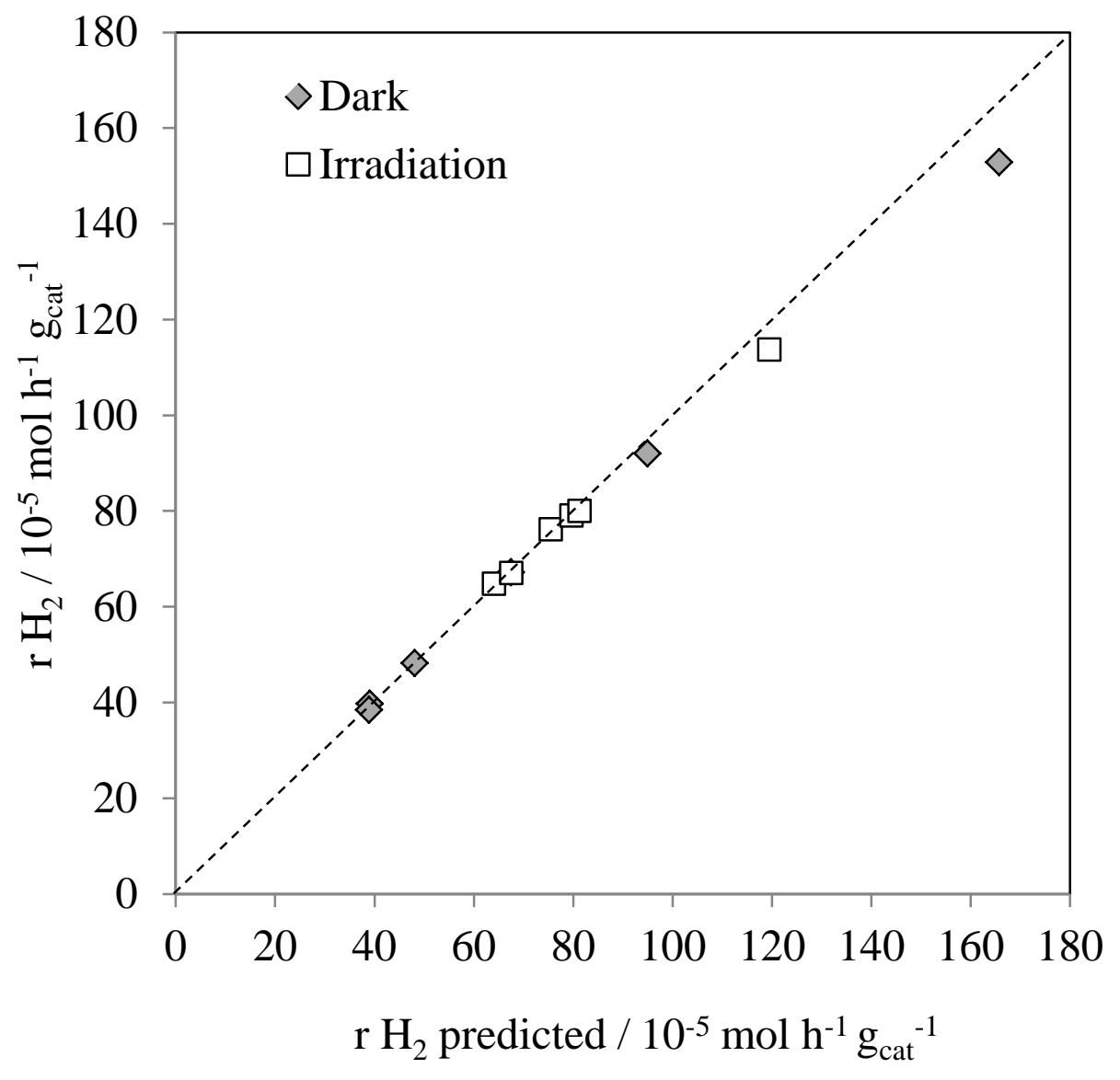

Figure 4. $\mathrm{H}_{2}$ production rate $\left(\mathrm{r}_{2}\right)$ vs. predicted $\mathrm{H}_{2}$ rate according to eqn (3) using the rate data in Figure 3. 


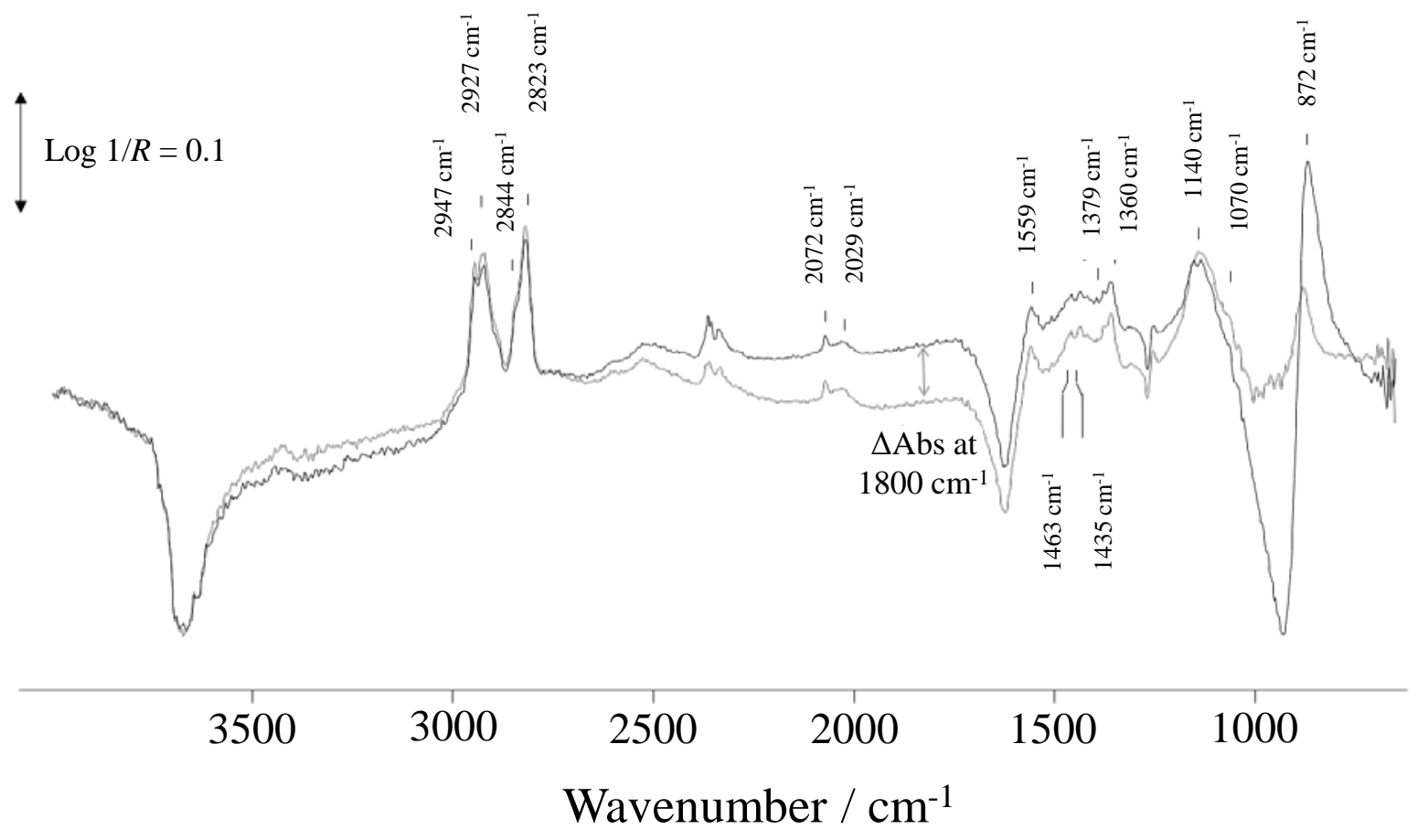

Figure 5: DRIFT spectra of $0.2 \% \mathrm{Pt} / \mathrm{TiO}_{2}$ under $5 \% \mathrm{CH}_{3} \mathrm{OH}+10 \% \mathrm{H}_{2} \mathrm{O}$ feed at $100{ }^{\circ} \mathrm{C}$ (grey) and under $5 \% \mathrm{CH}_{3} \mathrm{OH}+10 \% \mathrm{H}_{2} \mathrm{O}$ feed at $100{ }^{\circ} \mathrm{C}$ after $14 \mathrm{~s}$ of $\mathrm{UV}$ irradiation (black). Spectra have been corrected for gas phase methanol. 


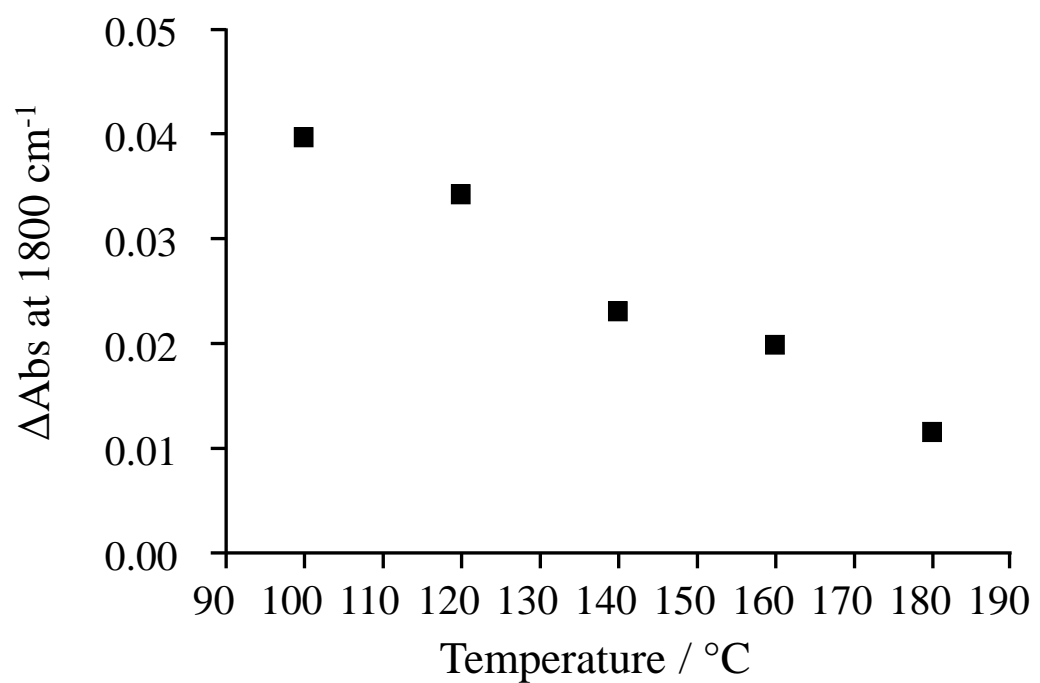

Figure 6: Change in absorbance at $1800 \mathrm{~cm}^{-1}$ after $14 \mathrm{~s}$ of UV irradiation for $0.2 \% \mathrm{Pt} / \mathrm{TiO}_{2}$ under $5 \% \mathrm{CH}_{3} \mathrm{OH}+10 \% \mathrm{H}_{2} \mathrm{O}$ feed at increasing reaction temperatures. 


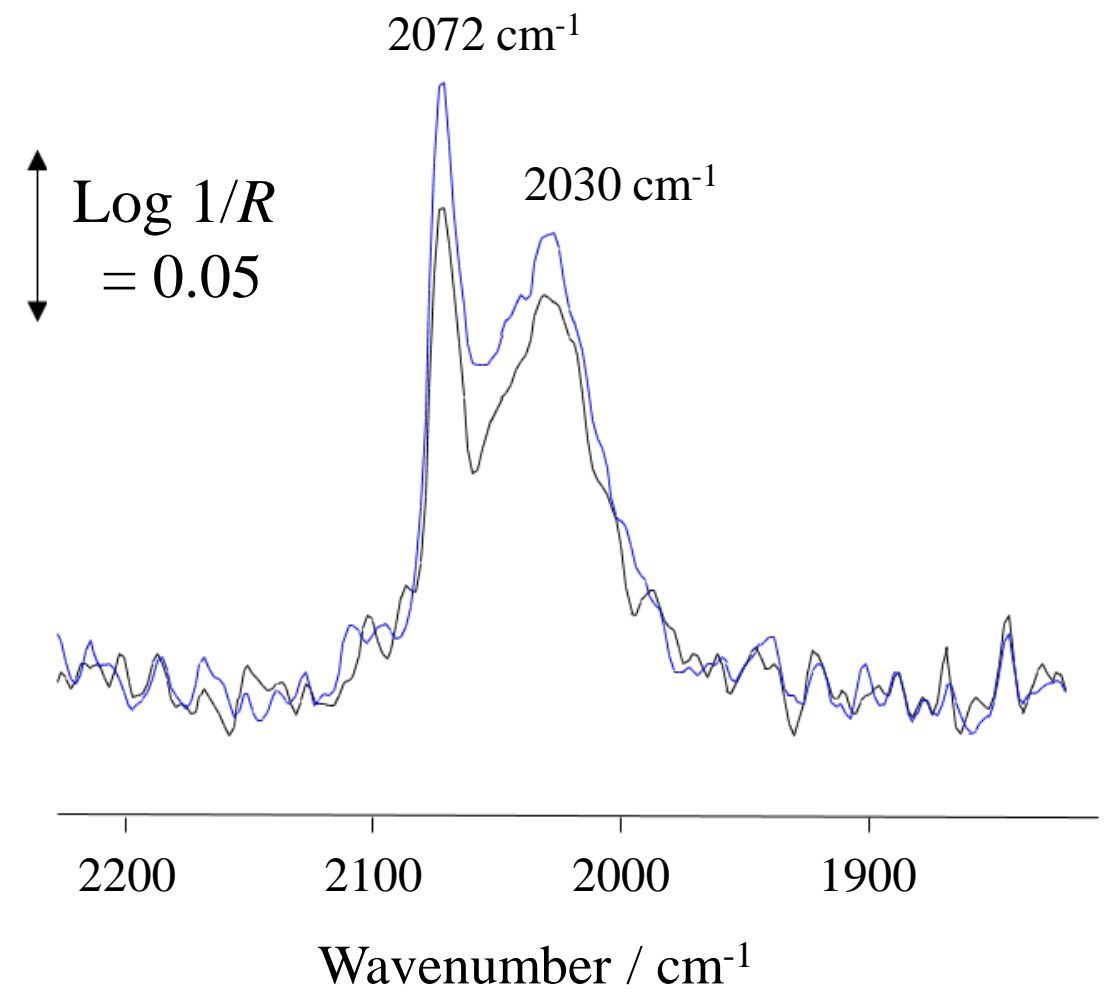

Figure 7: DRIFT spectra of Pt-CO bands at $100{ }^{\circ} \mathrm{C}$ in dark (blue spectrum) and under UV irradiation (black spectrum) 


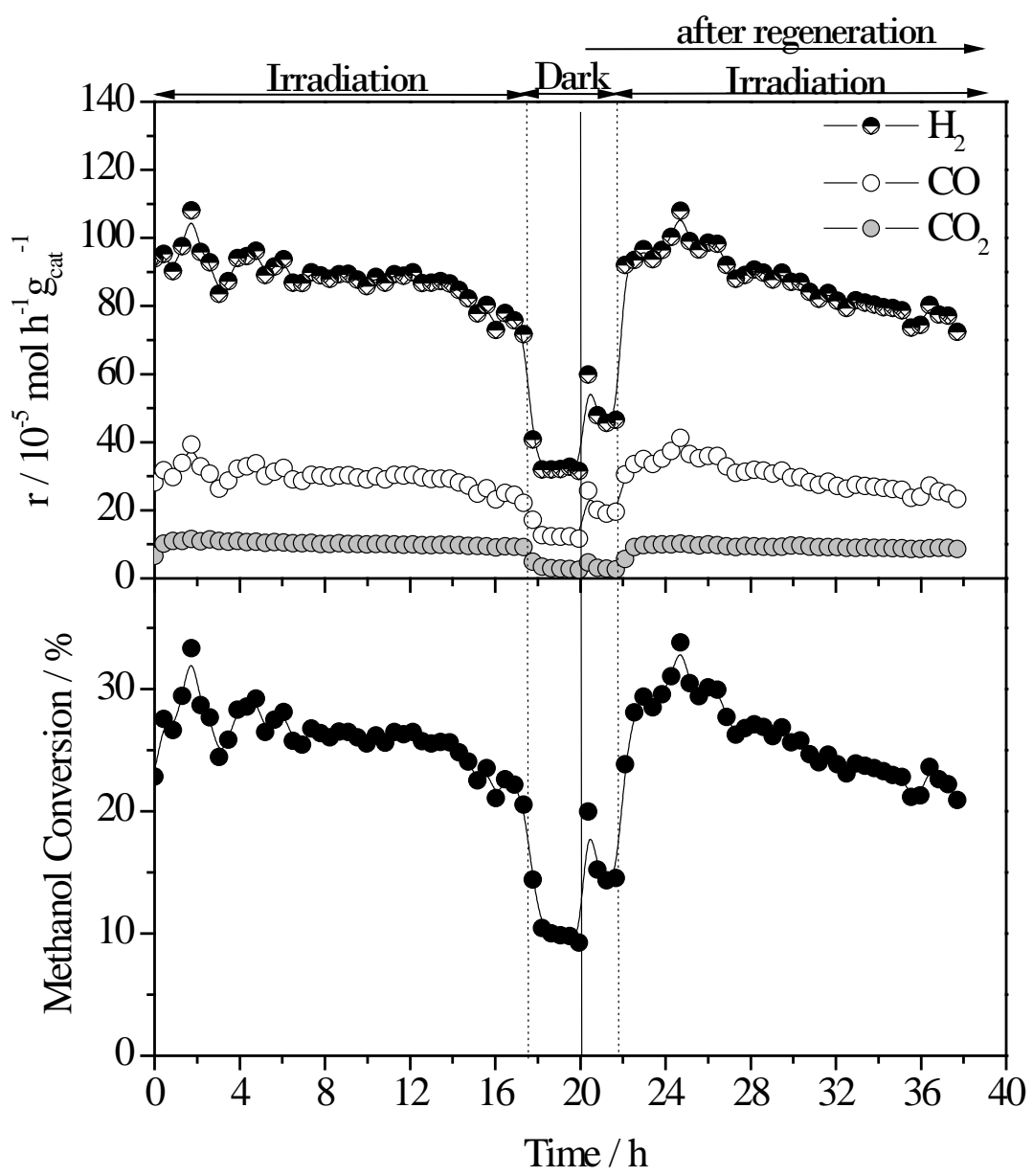

Figure 8. Effect of the photoirradiation of the catalyst in the production of $\mathrm{H}_{2}, \mathrm{CO}, \mathrm{CO}_{2}$ and methanol conversion. Reaction conditions: $800 \mathrm{mg}$ catalyst $\mathbf{0 . 2} \% \mathbf{P t} / \mathbf{T i O}_{2}(\mathrm{P} 25), 120{ }^{\circ} \mathrm{C}, 5$ $\% \mathrm{MeOH} / 10 \% \mathrm{H}_{2} \mathrm{O}$, Total flow $10 \mathrm{~mL} \mathrm{~min}^{-1}$ (Ar carrier). Regeneration treatment: $120{ }^{\circ} \mathrm{C}$, non photo-irradiation, $16 \% \mathrm{O}_{2} / 20 \% \mathrm{H}_{2} \mathrm{O}, 12.5 \mathrm{~cm}^{3} \mathrm{~min}^{-1}$. Photoirradiation with $200 \mathrm{~W}$ $\mathrm{Xe} / \mathrm{Hg}$ lamp. 